\title{
CHEMISTRY IN THE EIGHTEENTH CENTURY
}

$\mathrm{A}^{\mathrm{N}}$ $\mathrm{N}$ international meeting was convened in Paris during September 11-13 by the Comité National Francais d'Histoire et de Philosophie des Sciences in the name of its president, Prince Louis de Broglie. It was timed to follow on the ninth International Congress on the History of Science, held this summer in Spain; and some of those attending did in fact reach Paris via Barcelona. The invited contributors were asked to review topics such as: phlogiston; the discovery of the gases ; the preparation of nongaseous chemicals; the reformation in chemistry; affinities; chemical biographies and works; chemistry and eighteenth-century science.

Final arrangements were completed by M. Maurice Daumas (Conservatoire National des Arts et Métiers) and he proposed to some thirty participants, when they assembled at the Conservatoire, six sessions incorporating twenty-five speakers, who would each be allowed thirty minutes for reading and discussion of their announced memoir. This Procrustean principle, genially supervised by the sessional chairman, worked out surprisingly well. A provocative précis, giving time for a rapid-fire of terse, ready commentaries in French or English, often threw very helpful flash-lights on an unfamiliar subject.

The largest single groups attending were from France and the United States; but a useful British contingent accompanied the representatives of Eastern Germany, Eire, the Soviet Union, Sweden, Switzerland and Yugoslavia. Some others, including Douglas McKie, were unable to attend; but this was a notable, perhaps a unique concentration of interest and authority on the history of chemistry.

Reference to individual contributions must be invidious. It is in any event the intention of the sponsors to publish, under a separate cover, the proceedings of this colloquium. These again surveyed such pivotal pillars of progress as Boerhaave, Black, Priestley and Lavoisier. If perhaps too little was heard on Henry Cavendish and J. B. Richter, other figures such as Bergman, Crawford, Cullen, Geoffroi, Kirwan, de Morveau, Scheele, Tillet and Watt were exhibited in refreshing detail.

To the minority of professional chemists in attendance, there may have been something a whit rarefied in the attention given to Maupertuis and Gaspard Monge; but these were balanced by the stiffly practical consideration given by Academician Arthur Birembaut to early gas-manipulation or by F. Greenaway to contemporary analytical chemistry. None surely will forget the calm finality with which $G$. Kersaint buried the unsavoury legend of the treachery of Fourcroy to Lavoisier ; Figourovskij straddling the difficulties of language and time in his projection of Lomonossov; Claude Secretan's cool, systematic appraisal of scientific personalities; the charming intervention of M. Braise, who now occupies the pharmacist's shop once served by Lavoisier's mentor, Guillaume-Francois Rouelle.

The formal sessions were extended to the lunchtable, where the exchangers of criticism, literaturereference and citation could communicate their ideas. There was also an exciting inspection of new acquisi- tions from Lavoisier's laboratory apparatus. (By an educative coincidence, Blériot's original biplane apparatus, in this jubilee year, was seen suspended from the ceiling of another room.) The foreign guests were permitted a privileged visit to the chemical archives of the Academy, an inspection of note-books by Lavoisier, and a glimpse of the meeting-rooms with their antique velvet, gilt frames, classic mouldings and individual microphones.

Personal and renewed impressions were of the countless historical trails that lead back to Newton and Boyle; the accepted importance of the chemistry of the Scottish universities in the eighteenth century; the long-delayed development of Stahlian doctrine in the hands of Macquer and Rouelle; the painstaking, sharp rescrutiny of the contributions by Lavoisier to chemical theory; the muddled yet stimulating notions of affinity; the factors and persons which foreran Dalton. An intimidating confusion of early schools and ideas, acquiring a laboured, significant sequence as the simple gases were isolated and understood; and there is still much historical material to arrange and digest before such studies bring full benefit.

In their development of chosen themes by address or in debate practically every speaker was mindful of the broader canvas against which the chemical feature must be examined. There was careful attention to contemporary physics, metallurgy and pharmacy; to economics and invention; even inevitably to politics, with some good-humoured interventions on delicate French and Irish situations. Here were specialists indeed, but specialists determined on an adequate setting of their studies even to "The Fifteen", the Mountain and Vinegar Hill. Humanism kept breaking in.

Much more than the usual formalities of praise must go to the organization of this conference. Informal, urbane, efficient, friendly, it produced the sadly impractical conviction that such meetings should be held more frequently, and always convened in Paris. Of still more lasting importance was the sense of community created. Historians of science and especially, one imagines, historians of chemistry must generally plough a somewhat lonely furrow, although there are seemingly a few sites of adequate appraisal and support. Here was the refreshment of friendly controversy, of actual and potential collaboration, and an atmosphere in which chemistry was seen as something even more than a magical technique, seen as a major factor in the climactic development of scientific method and modern science, as a bright particular strand in the culture pattern of Western mankind. On these last points the eighteenth century had already no doubts at all.

In some closing words of appreciation, Henry Guerlac used his graceful bilingualism to express our thankful sense of pleasure and profit from this occasion and hinted at a possible opportunity of meeting American colleagues in 1962. None commented on the very sparse German attendance or on the Italian absences which some later colloquium will surely find improved. 